\title{
The HIV/AIDS epidemic and changes in injecting drug use in Buenos Aires, Argentina
} La epidemia de VIH/SIDA y los cambios en el uso
inyectable de drogas en Buenos Aires, Argentina La epidemia de VIH/SIDA y los cambios en el uso
inyectable de drogas en Buenos Aires, Argentina

1 Intercambios: Asociación
Civil para el Estudio
y Atención de Problemas
Relacionados con las Drogas,
Buenos Aires, Argentina.
2 Facultad de Ciencias
Sociales, Universidad
de Buenos Aires,
Buenos Aires, Argentina.
Correspondence
D. Rossi
Intercambios: Asociación
Civil para el Estudio
y Atención de Problemas
Relacionados con las Drogas.
Corrientes 2548.
1o “E”. (1046) Ciudad de
Buenos Aires, Argentina.
drossi@intercambios.org.ar

Abstract

This article discusses the changes in injecting drug use from 1998 to 2003 in Buenos Aires, Argentina. The Rapid Situation Assessment and Response methodology was used to obtain the information. Quantitative and qualitative techniques were triangulated: 140 current IDUs and 35 sex partners of injection drug users (IDUs) were surveyed; 17 in-depth interviews with the surveyed IDUs and 2 focus groups were held, as well as ethnographic observations. The way in which risk and care practices among injecting drug users changed and the influence of the HIVI AIDS epidemic on this process are described. In recent years, the frequency of injection practices and sharing of injecting equipment has decreased, while injecting drug use is a more hidden practice in a context of increasing impact of the disease in the injecting drug use social networks and changes in the price and quality of drugs. Knowledge about these changes helps build harm reduction activities oriented to IDUs in their particular social context.

Harm Reduction; Street Drugs; HIV; Acquired Immunodeficiency Syndrome

\author{
Diana Rossi 1 \\ María Pía Pawlowicz 1 \\ Victoria Rangugni 1 \\ Dhan Zunino Singh 2 \\ Paula Goltzman 2 \\ Pablo Cymerman 2 \\ Marcelo Vila 1 \\ Graciela Touzé 2
}

\section{Introduction}

Injecting drug use has antecedents in different countries that date prior to the prohibition of the social use of heroine and cocaine. The hypodermic syringe had been invented in the early $19^{\text {th }}$ century and its use was not limited to the medical field, but was incorporated into drug use practices by various groups in both the East and West 1. In Brazil, Uruguay, and Argentina, injecting practice is more widespread than in other South American countries 2. Nevertheless, in all these countries very little was known about injecting drug use before the HIV epidemic. The importance of injecting use in HIV transmission in Argentina became evident both in the AIDS cases diagnosed and the high HIV prevalence among injection drug users (IDUs) 3 .

In the last 15 years, much of the research work on injecting drug use has focused on characterizing the risk practices for transmission of various infections, particularly HIV 4.

The current article is based on data obtained from a study performed in 2003-2004, during the second phase of the Regional Project on HIV/AIDS associated with drug use in the Southern Cone countries of Latin America. This research aimed to compile, update, and organize the available information on injecting drug use in relation to changes that occurred between 1998 and 2003. Among other aspects, the study attempted to describe the 
changes in injecting practices and their relationship to the HIV/AIDS epidemic 5 .

The information obtained in this study revealed changes in risk practices and care related to injecting drug use in Greater Metropolitan Buenos Aires (consisting of the city of Buenos Aires proper and surrounding municipalities), Argentina. Such changes followed a similar trend to those shown in various studies elsewhere in the world.

In New York, injecting practices were studied in 5,289 IDUs from 1990 to 1997, and a decrease was observed in shared use of injecting paraphernalia. However, there was a smaller decrease in risk practices in sexual relations involving both the stable partner and occasional partners 6 .

In Canada, changes were also shown in risk practices and care among IDUs 7 . Some studies have indicated that in Brazil this change has also been occurring among some sub-populations of IDUs 8 .

\section{Methodology}

The methodology was based on the principles of the Rapid Situation Assessment and Response. The study used an adaptation of the Rapid Assessment and Response Guide on Injecting Drug Use proposed by the Substance Abuse Program of the World Health Organization (SAP/WHO) and by UNAIDS 9. Projects based on this methodology are developed in a short period of time and focus on obtaining updated practical results that contribute to the design of appropriate preventive strategies 10 .

The study included information gathered through quantitative and qualitative techniques. A questionnaire with closed and open questions was applied to 140 IDUs and 35 sex partners of IDUs, followed by in-depth interviews with 17 of the 140 IDUs. Two discussion groups were held with IDUs and former IDUs, along with ethnographic observations. The fieldwork was conducted from May 2003 to January 2004. This article reports on the data constructed from the questionnaires, in-depth interviews, and discussion groups, focusing on current practices and those used by the interviewees 6 years previously, by means of comparative questions in the data collection instruments. This produced information on changes in injecting use from 1998 to 2003.

The injecting drug use sample was intentional, consisting of individuals more than 18 years of age who had injected drugs at least once in the previous three months (to guarantee con- tact with current consumers), and who participated voluntarily in the study. Of the 140 IDUs who answered the questionnaire, 72 had some regular contact with a syringe-exchange program (SEP), while the other 68 had no such contact.

Informed consent was obtained, describing the study objective and ensuring anonymity and confidentiality. The interviewees received the names and telephone numbers of the persons in charge of the study so that they could contact them if they so desired. All the study participants received orientation and preventive information immediately after the data collection techniques were applied.

It is important to recall that given the stigma they experience and the legal repression of certain drugs such as cocaine, IDUs belong to what are considered "hidden populations" that are difficult to access to apply data collection techniques. This situation hinders the use of a probabilistic sample, since questions concerning stigmatized and illegal practices can produce answers with dubious reliability. Therefore, many studies of IDUs employ non-probabilistic samples, especially when seeking to interview individuals that are not in treatment centers, for whom less information is usually available and who in many cases have a limited relationship with institutions and live in situations of exclusion and social vulnerability 11,12.

Intentional selection of the sample was linked to the ties of trust built in the community outreach work by organizations working from a harm reduction perspective. The "snowballing" sampling technique was used. Recruitment was done by the peer educators from different harm reduction programs in Greater Metropolitan Buenos Aires, which guaranteed the ties of trust with the IDUs and their sex partners. The research group is also part of a nongovernmental organization that conducts one of the oldest harm reduction programs in Buenos Aires.

\section{Results}

The IDUs in this study resided in Greater Metropolitan Buenos Aires, and the sample was predominantly male (89.3\%). Age ranged from 18 to 53 years, with a mean of 33 years. Some $59.3 \%$ had partners and slightly over half of the IDUs (54.3\%) had children.

The majority (71.4\%) treated their health problems in the public health care sub-system (hospitals and/or health centers). This population is characterized by multiple drug use, since many of the interviewees also frequently consumed cannabis $(78.6 \%)$, alcoholic bever- 
ages $(65.7 \%)$, inhaled cocaine $(63.9 \%)$, and benzodiazepines (49.3\%).

Among the relevant socioeconomic data, modes of subsistence of the IDUs, as asked in the question "How do you make money?", highlighted the impact of the Argentine economic crisis on this population. This question was answered in relation to activities oriented towards the material reproduction of their lives that were not limited to access to work, both in the year 2003 as well as in 1998. There were multiple responses. There was an increase in unemployment in this population, since $54 \%$ of the IDUs reported that they were working in 1998 , as compared to only $40 \%$ by 2003 . In addition, there was an increase in sporadic or discontinuous work, referred to in Argentina as "changas" (odd jobs) from $12.2 \%$ to $32.9 \%$. There was also an increase from $0.7 \%$ in $18.6 \%$ in those who received some kind of government support. Nevertheless, the proportion of those who reported living from illegal activities remained stable between 1998 and 2003.

\section{Changes in frequency of injecting use}

According to this study, current injecting drug practices differ from those of the past in various aspects.

The number of years in which individuals had been injecting drugs was distributed quite homogeneously: $16.4 \%$ had been injecting for fewer than 5 years; $20 \%$ from 5 to 9 years; $22.9 \%$ from 10 to 14 years; $20.7 \%$ from 15 to 19 years; and $20 \%$ for more than 20 years. Although the process of change was studied primarily from 1998 to 2003, this distribution allowed obtaining information on injecting practice in the last three decades, which in turn allowed a broader historical perspective.

The most frequently injected substance was cocaine (87.1\%), followed by morphine (10\%). There are substances that the same individuals had used in the past, such as amphetamines salt, which they no longer use as frequently. Some $35.3 \%$ of the IDUs had used amphetamines salt in the past ("ever used"), but none currently, since this substance was replaced in the mid-1980s by cocaine, which is easier due to access because it is so widespread.

Meanwhile there was a decrease in the frequency of current injecting in the IDUs as compared to 1998, particularly daily injecting, which dropped from $43.6 \%$ in 1998 to $5 \%$ in 2003 , showing a statistically significant difference (McNemar test $\mathrm{p}<0.001$ ), as shown in Figure 1.

The frequencies of injecting two or three days a week and on weekends were those that remained most constant, and there was an increase in the percentage of users who injected at more extended intervals.

The qualitative information indicates that the decrease in frequency is related to the low

Figure 1

Frequency of injecting drug use. Buenos Aires, Argentina, 1998-2003.

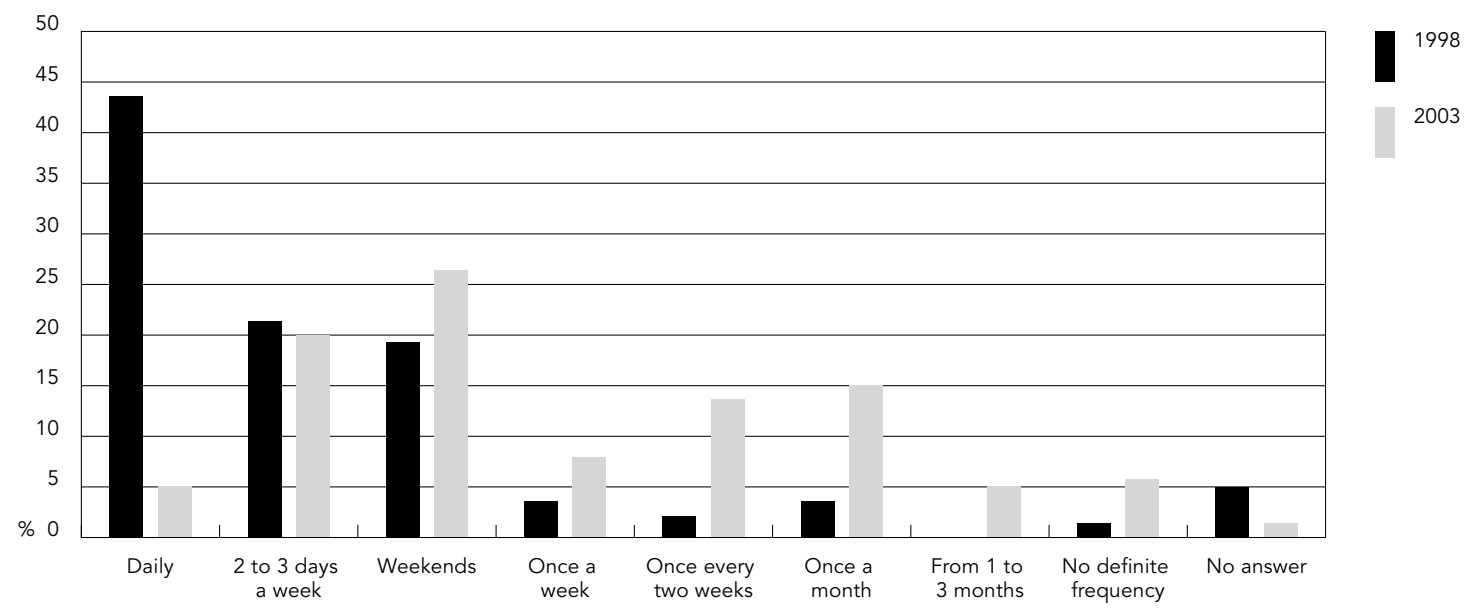

$\mathrm{n}=140$. 
quality of the cocaine as compared to the quality obtained at the same price before the devaluation of the Argentine peso with the economic crisis in 2001. The decrease in frequency was also associated with care for self and others. While we did not obtain sufficient information to observe a change in the drug use route among the interviewees, the lower frequency of injecting use suggests that drug use by other routes is more habitual.

"When I started consuming, a paper [dose of cocaine] cost 20 pesos. It cost 20 pesos and weighed a gram. Nowadays it costs five pesos and weighs less than half a gram. But what's the deal? It's not the same quality. And when I started shooting up, I consumed more than I do now. Thing is, I'd have six papers, and with each paper I'd shoot up once, and so that made a total of six hits. And you get used to it, because it's not good quality. What I'm buying now is not bad, but it's not good, either. So not long after you shoot up, you come down. So what used to get you high six times is now just good for three hits" (man, 35 years).

"First I started shooting up cocaine all the time, and Ketalar for a while, too. But it wasn't cool, because I was living just to get high, but now I have other priorities. I can say, 'No, I don't feel like it today, I'm not going to shoot up, not today, not tomorrow, either.' Now I have the power to decide" (man, 34 years).

\section{Where are the users you don't see?}

Another change in injecting use is that it has become a more hidden and individual practice. In many cases the IDUs do not talk about their injecting practice even with their partners. Their silence is related to the stigma that associates drug injecting with AIDS and death.

The transition to a more individual experience is statistically significant (McNemar test $\mathrm{p}<0.001$ ). An estimated $80 \%$ of the interviewees had injected with others at some moment in their lives, while only $42.4 \%$ maintained this collective use in 2003.

This was also perceived clearly by $65 \%$ of the IDUs, who strongly agreed with the statement "Now we shoot up alone".

The reasons reported by those who inject alone included arguments associated with greater enjoyment, not wanting to inject others or have others injecting oneself, individual consumption being "less complicated", and avoiding "distrust" and possible "lack of control".

Of the 59 IDUs who reported currently injecting with others, $66.1 \%$ did so with their friends and $18.6 \%$ with their partners. The IDUs who always injected with others showed a higher proportion of partners who also injected (64.3\%, as compared to $22.2 \%$ of those always injected alone and who had partners).

The circumstances and place for injecting drugs also changed. A few years ago, injecting locations were not exactly public spaces, but they were also not the domestic environment as now, according to the majority of the interviewees. IDU networks not only knew each other, but were also linked to other networks from other territories, often procuring drugs or other kinds of interactions. Currently it is very difficult to find broad injecting use networks. Those who continued to shoot up with others in 2003 were doing so mainly with their friends.

\section{The view of IDUs' sex partners}

When IDUs were asked if they had ever had a partner who injected drugs, nearly all of the women answered in the affirmative, as opposed to only $39.7 \%$ of the men. This shows that as compared to men, injecting use by women is linked more to that of their partners.

Many IDUs were hiding their injecting practice even from their closest contacts. Since injecting usually leaves marks on the body, hiding it from one's partner is extremely difficult. However, there appeared to be a kind of "complicity" in some couples or in the circle of friends, "as if" they did not see anything different about the IDU's body. Therefore, even in the individual's most private sphere, the practice remains concealed, unknown.

Some $34.3 \%$ of the sex partners of IDUs did not talk with their partners about their injecting, for the following purported reasons: they were impressed or wanted to avoid arguments, discomfort, or even abuse. It was one of those issues "you don't talk about". In this same sense, $47.2 \%$ did not know whether their partners had ever shared syringes. According to the partners:

"He doesn't like to talk about it. If I bring up the subject, he yells at me, beats me. He doesn't want anybody messing with the issue" (woman, 20 years).

"It just never came up between us" (man, 43 years).

"I've been through so many hassles already, I don't want to talk about it. If he does it [injects], he doesn't talk to me about it, so I won't get uptight" (woman, 36 years).

Many IDUs and partners of IDUs highlighted that soon after injecting, their interest in having sexual relations decreased. Partners stated 
that when IDUs shot up, they displayed rejection/disgust/strangeness, instilled fear, and did not want any physical contact with their partners.

"I felt disgusted, didn't want [sex], felt sick, didn't feel like it" (woman, 26 years).

"I feel rejection, because he gets high from shooting up, not from me" (woman, 41 years).

\section{Relationship between injecting drug use and HIV/AIDS}

According to data from the Argentine Ministry of Health, injecting use was the largest transmission route of all the accumulated AIDS cases in Argentina from 1982 to October 2004 (33.5\% of 26,832$)$, followed by $29.1 \%$ heterosexual transmission and $18.7 \%$ men who only have sex with men 13.

The evolution in transmission categories among individuals over 12 years of age shows that in males until 1996, injecting drugs (46.5\%), homosexual transmission (30.1\%), and heterosexual transmission (17.8\%) were the principal causes of transmission in new cases and increased yearly. However, since 1996 the heterosexual route has continued to increased, while there was a trend towards reversal among IDUs and men who have sex with men (MSM). The trend also changed among women, and currently the most frequent transmission route is heterosexual, with $80 \%$ of the cases.

The first AIDS case from injecting drug use in Argentina was diagnosed in 1985. All the country's provinces have reported cases, but the largest percentage is concentrated in the province of Buenos Aires and in the City of Buenos Aires. In 2003, a comparative analysis was published with 22 studies on HIV seroprevalence in IDUs, conducted in Argentina from 1987 to 1999 . According to the data, more than $95 \%$ of the IDUs injected cocaine and there was a high HIV infection rate in this population, ranging from $27 \%$ to $80 \% 14$.

The impact of the AIDS epidemic among IDUs has been observed in other studies in the region 15,16. In the case of Buenos Aires, the collected data reflects its influence on changes in injecting patterns. The following excerpt from a discussion group of male IDUs and former IDUs ranging from 24 to 50 years of age shows this association: "Many died. There was a huge scare, ten years ago. People were scared by so many deaths, basically more from HIV than from overdose" (man, 35 years).

Many of the older IDUs participating in the study considered themselves "survivors" of var- ious groups of friends and family with whom they were linked in drug injecting. These data are similar to those from the first study on seroprevalence of HIV and other viruses with 174 non-institutionalized IDUs in Greater Buenos Aires, in which $82 \%$ had lost friends or relatives due to AIDS 17.

In our sample of 140 IDUs, $87.9 \%$ had lost friends, acquaintances, partners, and/or relatives to AIDS in recent years. Of this group of deceased individuals, $79.7 \%$ were friends, $18.7 \%$ acquaintances, $13 \%$ siblings, and $9.8 \%$ partners of the interviewees.

Figure 2 shows the variation in the reported number of friends, relatives, and acquaintances who died from AIDS, according to year of death.

The mortality rate from AIDS from 1990 to 2001 published in the Boletín sobre el Sida en la Argentina [AIDS Bulletin, Argentina] shows an upward curve until 1996, beginning to drop and stabilize in the subsequent years. However, comparing this with the information provided by the IDUs, it would appear that among the peers and relatives of this population, many deaths were concentrated in recent years. Although the impact of more recent deaths may have influenced the interviewees' recall, one hypothesis emerging from this information is that IDUs have had little access to HIV treatment. There may have been an impact from the distance between the IDUs and the health system, often aggravated by the refusal of many Departments of Infectious Diseases to provide antiretroviral treatment to individuals who continue to use drugs 18,19 .

The death of friends and acquaintances due to AIDS also led to changes in condom use. Many IDUs emphasized how the HIV/AIDS epidemic led them to care for themselves and to spread ways of preventing HIV transmission among their peers, especially the younger ones.

"When AIDS came on the scene, a lot of people didn't give a shit, and there they are. But many of us opened our eyes and said: 'No, wait, did you see how that dude died?'Yeah, we'd better all wise up, or we're going to kill each other! And this was back in 1989 and 90, because before that we didn't know anything. There was no information of any kind. We had to get wise because a friend died of AIDS, not because they handed us a leaflet, like now when we fight to pass out leaflets or share condoms. We all dig it now. But back in 90 there was nothing. Nobody knew what sharing your works could do to you, let me tell you, not a single rubber, or what rubbers were good for" (man, 33 years).

In relation to HIV testing, $72.1 \%$ had been tested since $1990,51.4 \%$ of whom were positive, 


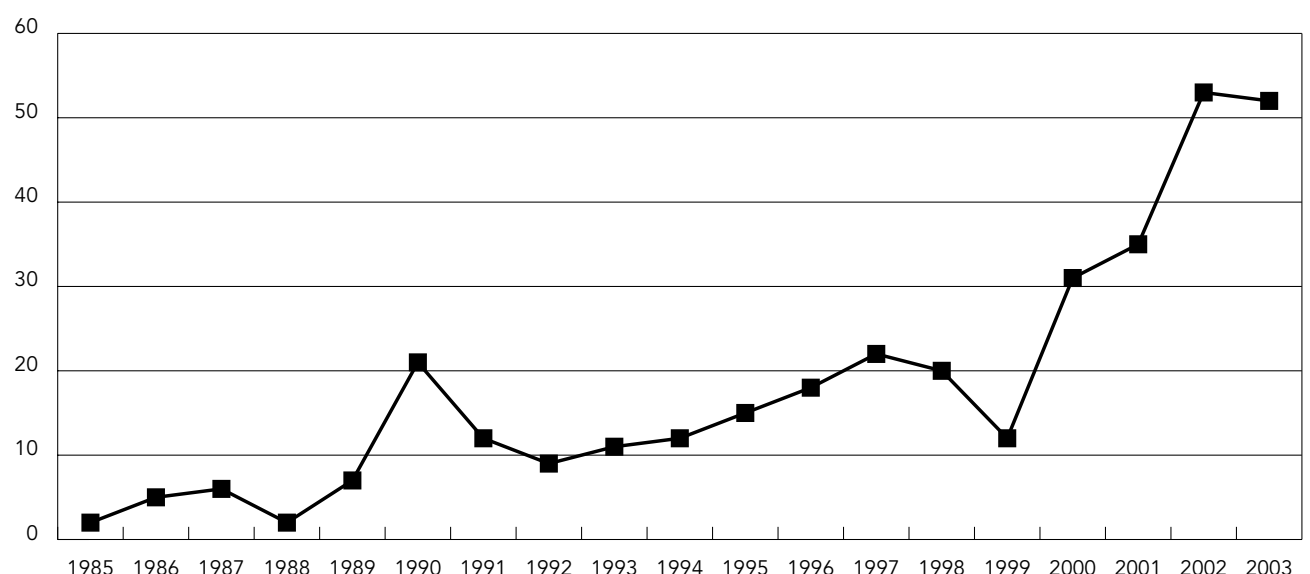

Note: more than one answer allowed $(n=345)$.

$43.6 \%$ negative, $3 \%$ did not know, and $2 \%$ did not answer the question.

Among the individuals who tested HIV-positive, this fact led to changes in their lives such as greater care with the own body and mode of injecting, care to avoid transmission, and fear of (or even abstinence from) sexual relations. Some reported changes in the drug consumption route.

"Today they tell me to go shoot up like I used to. No. What's changed is that now I watch out for myself, because now I know what HIV means. I know what it is. The sharing has changed, and I tell my friends, 'Dude, watch out, cause you can get infected'. Because a lot of my friends are gone, a heap of my friends died of HIV. And not just from shooting up" (woman, 29 years).

When the IDUs were asked which diseases they considered the most serious, the most frequently mentioned were HIV/AIDS (95\%), cancer (46.8\%), and hepatitis (28.8\%). HIV/AIDS was also the most common disease $(77.9 \%)$ among acquaintances of the interviewees (Figure 3).

Although cancer was mentioned as a much less common disease than others among acquaintances of the interviewees, it was considered the second most serious. These answers may reflect the impact of social representations on the construction of the notion of health/ disease. Only $2.9 \%$ considered addiction a serious disease, while $10 \%$ recognized it as a health problem among their acquaintances. This indicates that the interviewees do not perceive drug use as a disease.

\section{Changes in sharing of injecting equipment}

Death of injecting friends or acquaintances due to AIDS, fear of HIV, or living with HIV appear repeatedly as the basis for new precautions by IDUs in relation to sharing injecting equipment, even though such precautions have been adopted unevenly.

"You see a lot of people are gone, it's crazy, I know a lot of them are gone. But dude, nobody forces you to do anything. If you want to shoot up, whammo, you do it, dude? To snort instead of shooting up is in your mind. When I shoot up, I use my own works, dude. You shoot up, and you don't share the hit with anybody, just you" (man, 35 years).

In this group the habit of sharing syringes among injectors is declining, and is less frequent among younger injectors.

Of the 140 IDUs, 59 reported currently injecting with others, and they were asked whether they had shared syringes in the previous month. Some $\mathbf{2 8 . 8 \%}$ had lent or borrowed syringes, while the others denied sharing (they had neither lent nor borrowed).

There was also a decrease in the number of times these same individuals used each syringe. At the time of the survey (2003), some $81.4 \%$ used the same syringe one to three times. In 1998, some $30 \%$ of the IDUs reported using the same syringe from five to ten times. In relation to changes in frequency of use, this would 
Diseases considered most serious and health problems among friends, relatives, and acquaintances.

Buenos Aires, Argentina.

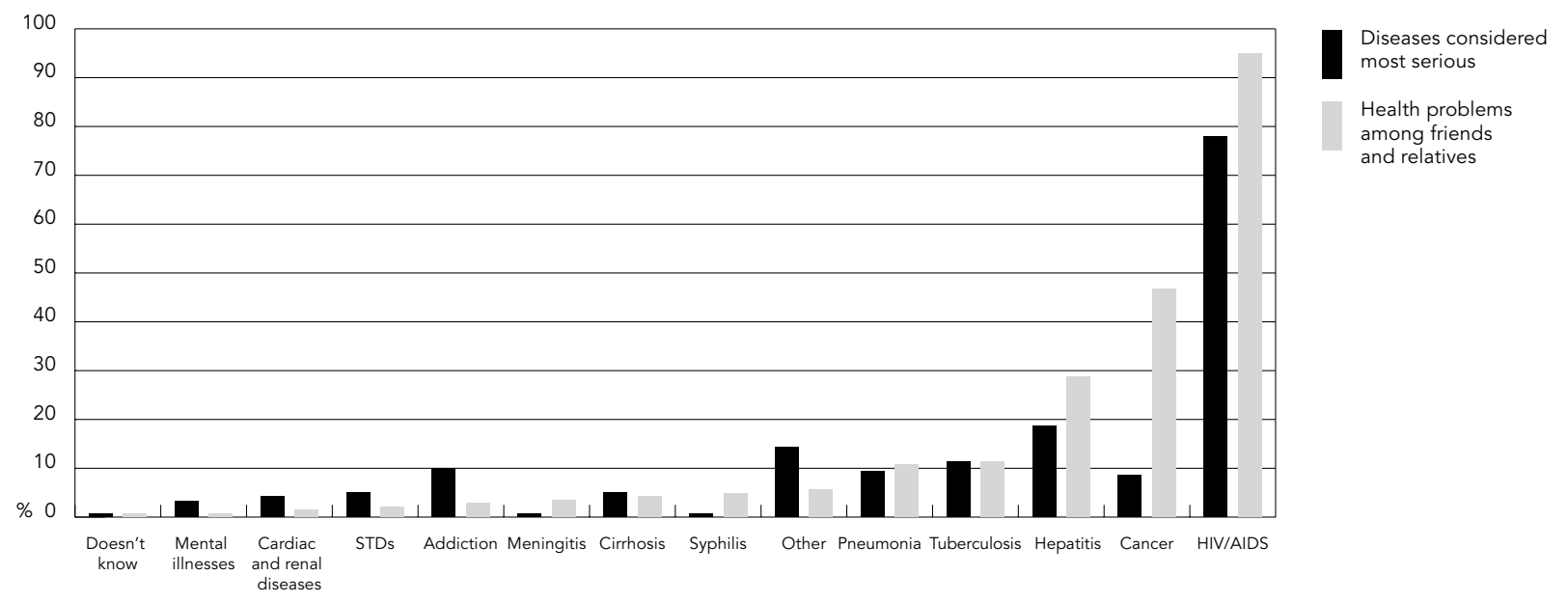

Note: more than one answer allowed $(n=140)$.

indicate greater consumption in 1998 than later in 2003, since the higher number of times using the same syringe was combined with greater frequency of daily use in the past.

Just as injecting with others appears to have been a more widespread practice in previous years, shared use of injecting equipment was also more common in 1998, as shown in Figure 4. Fisher's test with $\mathrm{p}<0.001$ was done for each type of injecting material.

Of all the IDUs interviewed, $51.4 \%$ had regular contact with some harm reduction program in 2003. Shared use of injecting material was more common among IDUs who had no contact with a harm reduction program.

As shown in Figure 5, while shared use of syringes reached $40 \%$ among IDUs who had no contact with harm reduction programs, this percentage dropped to $17.2 \%$ among those who had contact with HRPs.

As for shared use of other injecting materials, the tendency was similar. The in-depth interviews revealed references to the importance of having access to injecting materials, condoms, and especially information on risk management strategies allowing users to care for themselves and others.

"As time passed, a lot of things changed. Today you can get syringes here [a peer educator's home]. You used to have to beg all over the 'hood for forty cents, because you already had the five bucks for the paper. If you didn't beg for the forty cents for the syringe, you didn't shoot up. That's how it is if you don't bring your syringe, I'm not lending mine or borrowing from anybody either. It used to be one syringe for everybody, it was always like that" (man, 34 years).

Comparing IDUs with and without contact with harm reduction programs and considering that the majority of the programs began operating in 1999, we observed the effectiveness of harm reduction activities in relation to shared use of injecting equipment.

\section{Discussion}

The study data show various changes in relation to injecting use in recent years. The impact of the AIDS epidemic among IDUs is still associated with high mortality in this population, especially in the absence of interventions favoring access and adherence to antiretroviral treatments, as demonstrated by recent North American studies with drug users 20,21 . The high mortality rate in this population was also verified by a study analyzing the profile of AIDS deaths in 100 patient histories in a Buenos Aires hospital from June 2003 to March 2004, 41\% of whom had a history of injecting drug use 22.

In our study, the impact of AIDS mortality on the social networks closest to the IDUs is 
Figure 4

Shared use of injecting equipment. Buenos Aires, Argentina, 1998-2003.

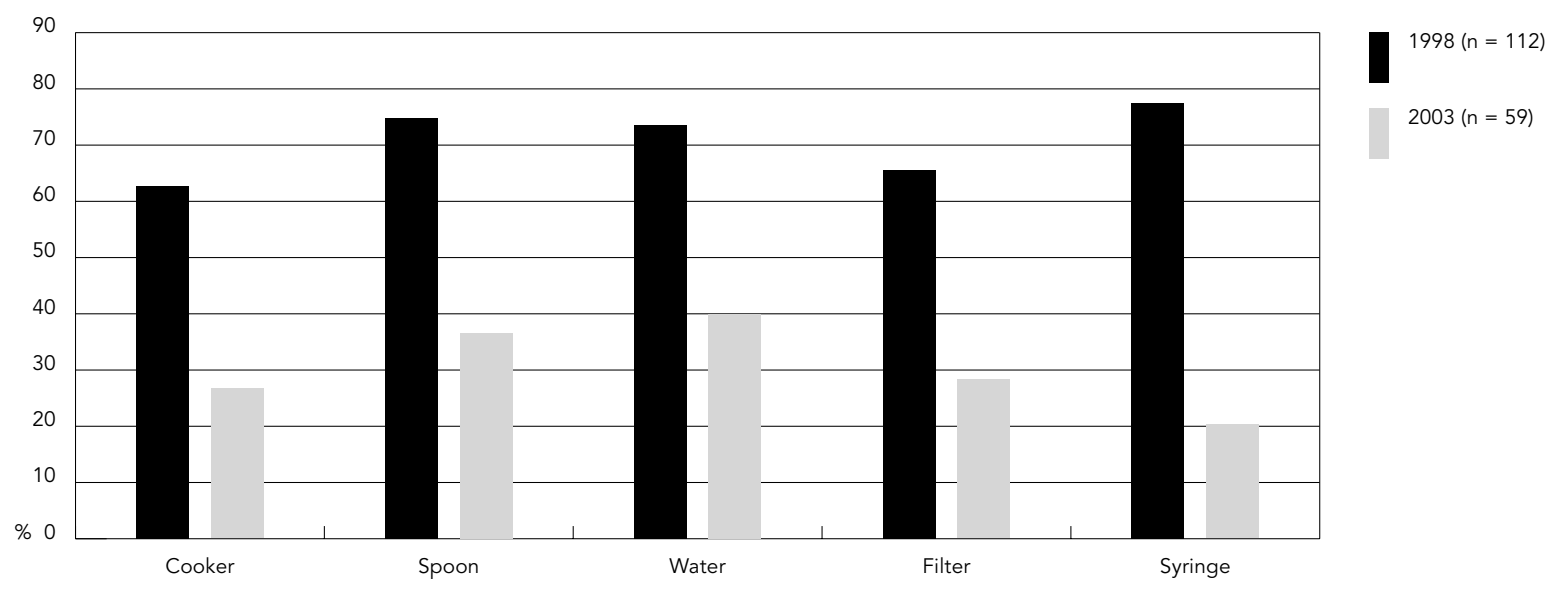

$p<0.001$.

Figure 5

Shared use of syringe in the previous month according to syringe-exchange program (SEP). Buenos Aires, Argentina.

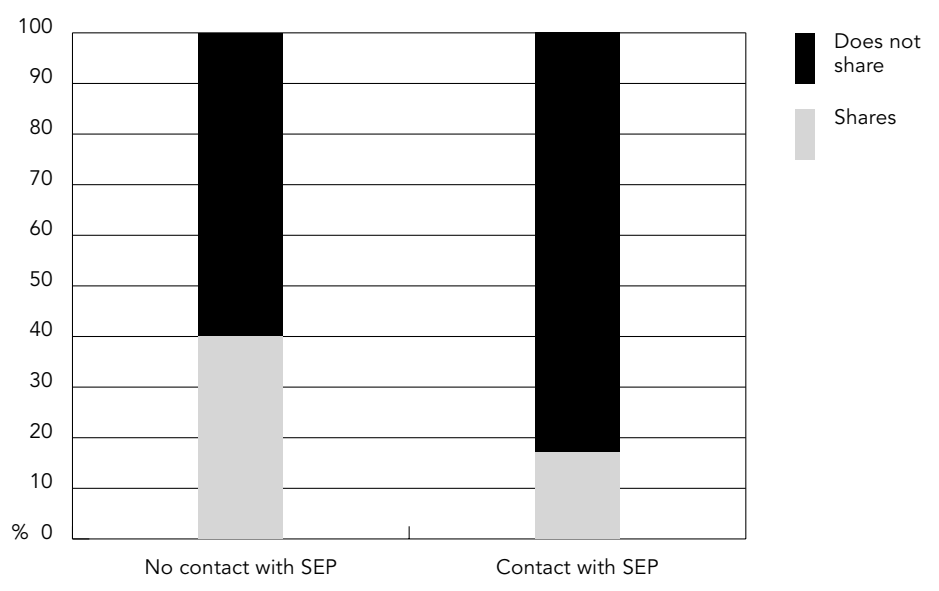

one of the main reasons for changes in drug use patterns. Added to awareness of the spread of HIV among IDUs in the late 1980s was the high number of deaths of IDUs beginning several years later and the recent deaths among relatives, friends, and acquaintances, while official figures on the epidemic indicate leveling off of the mortality curve in individuals diagnosed with AIDS.

The study showed changes in the mode of injecting, which now tends to be more individual, especially in the home environment. Since many IDUs do not talk about their injecting practice even with their partners, injecting use has not only become more hidden, but also more silent. The idea is definitely to avoid recognition as an injecting drug use, since the practice is heavily stigmatized and thus associated with negative effects: the disease (AIDS) and death. Nevertheless, a dimension of pleasure has survived in injecting use that does not clash with risk perception, but rather helps foster risk management initiatives. The perception of risk related to sharing the syringe also combines with the search for pleasure in intimacy, that is, the solitary pleasure allowing to safeguard oneself from the view of others.

Both in single and group injecting practice, the same syringe is used fewer times than in the past, which is associated with a decrease in the frequency of injecting use. The arguments for this change do not appear to be related to 
more limited affordability, but to ways of managing care by many of the injecting drug use interviewees. The decrease in the frequency of drug use is also related to the bad quality of the cocaine currently sold, which is not enjoyed as in the past because it does not allow the desired effect from injecting use.

In addition, as observed in other cities around the world 23,24 , harm reduction programs have facilitated risk and health management, particularly among users that have been in contact with such programs for several years, even though the 2001 Argentine economic crisis also had a negative impact on services in different harm reduction programs. The positive impact of harm reduction programs is observed in the decrease in sharing syringes, which is related to the increase in information on health risks and the continuous provision of preventive elements like injecting materials and condoms, with free and continuous access.

\section{Resumen}

Este artículo refleja los cambios en el uso inyectable de drogas producidos entre 1998 y 2003 en Buenos Aires, Argentina. Para obtener la información se empleó la metodología de Evaluación y Respuesta Rápida, triangulando técnicas cuantitativas y cualitativas. Durante 2003-2004 se realizaron encuestas a 140 usuarios de drogas inyectables (UDIs) actuales y a 35 parejas sexuales de UDIs. De este universo, 17 UDIs fueron entrevistados en profundidad; se formaron dos grupos de discusión y observaciones etnográficas. Se describe el modo en que cambiaron las prácticas de cuidado y riesgo en el uso inyectable y la influencia de la epidemia de VIH/SIDA en este proceso. En los últimos años disminuyó la frecuencia de uso y del uso compartido de material de inyección, se incrementó el ocultamiento del uso inyectable; en un contexto de fuerte impacto de la enfermedad en el entorno cercano a los UDIs y de un cambio en la relación precio-calidad de las drogas. Conocer estos cambios permite intervenir más adecuadamente en la reducción de los daños asociados al uso inyectable de drogas en el contexto particular en que estas prácticas se desarrollan.

Reducción del Daño; Drogas Ilícitas; VIH; Síndrome de Inmunodeficiencia Adquirida

\section{Contributors}

D. Rossi coordinated the research and participated in drafting the manuscript. V. Rangugni analyzed the data and supervised the fieldwork. M. P. Pawlowicz and D. Z. Singh elaborated the manuscript and participated in the data analysis. G. Touzé participated in the review of texts. P. Goltzman and P. Cymerman participated in designing the techniques and processing the data. M. Vila collaborated in the statistical analysis.

\section{Acknowledgments}

The project was supported by the Joint United Nations Program on HIV/AIDS (UNAIDS) and the United Nations Office on Drugs and Crime (UNODC). We wish to acknowledge the collaboration, during data collection, by the civil society organizations SSR en el Sur, Convivencia (PWA), and El Retoño, the STD/AIDS Program of the Municipality of General San Martín, and the Social Orientation Center for Family and Youth of the Municipality of San Fernando.

We also acknowledge the contributions by the study's Advisory Committee: Gabriela Hamilton, Sonia Quiruelas, Claudio Bloch, and Mercedes Weissenbacher. 


\section{References}

1. Stimson G, Des Jarlais D, Ball A. Drug injecting and HIV infection: global dimensions and local responses. London: World Health Organization/ UCL Press; 1998.

2. Touzé G, Magis-Rodriguez C, Marques LF. HIV and injection drug use in Latin America. AIDS 2002; 16 Suppl 3:34-41.

3. Rossi D, organizador. Sida y drogas. Reducción de daños en el Cono Sur. Buenos Aires: Programa Conjunto de las Naciones Unidas para el SIDA/ Intercambios Asociación Civil y Unidad Coordinadora Ejecutora de VIH/SIDA y ETS; 2001.

4. Bravo MJ. Infecciones de transmisión sanguínea o sexual entre las personas que se inyectan drogas y sus parejas en las Américas. Manual para profesionales de la salud. Washington DC: Agencia Española de Cooperación Internacional/Ministerio de Sanidad y Consumo de España/Organización Panamericana de la Salud; 2004.

5. Rossi D, Rangugni V, organizadores. Cambios en el uso inyectable de drogas en Buenos Aires (19982003). Buenos Aires: Intercambios Asociación Civil, Ministerio de Salud y Medio Ambiente de la Nación/Programa Conjunto de las Naciones Unidas para el SIDA/Oficina de las Naciones Unidas para el Control de las Drogas y el Delito; 2004.

6. Des Jarlais D, Perlis T, Friedman SR, Chapman T, Kwok J, Rockell R. Behavioral risk reduction in a declining HIV epidemic: injection drug users in New York city, 1990-1997. Am J Public Health 2000; 90:1112-6.

7. Brogly SB, Bruneau J, Vincelette J, Lamothe F, Franco EL. Risk behavior change and HIV infection among injection drug users in Montreal. AIDS 2000; 14 Suppl 16:2575-82.

8. Telles PR, Bastos FI, Guydish J, Inciardi JA, Surrat HL, Pearl M, et al. Risk behavior and HIV seroprevalence among injecting drug users in Rio de Janeiro, Brasil. AIDS 1997; 11 Suppl 1:35-42.

9. Touzé G, Rossi D, Cymerman P, Ereñu N, Faraone S, Goltzman P, et al. Prevención del VIH/SIDA en usuarios de drogas. Resultados de un proyecto de investigación. Buenos Aires: Intercambios; 1999.

10. Stimson G, Fitch C, Rhodes T, Ball A. Rapid assessment and response: methods for developing public health responses to drug problems. Drug Alcohol Rev 1999; 18:317-25.

11. Wiebel WW. Identifying and gaining access to hidden populations. NIDA Res Monogr 1990; 98:4-11.

12. Qualitative European Drug Research. Workgroup review of qualitative research on new drug trends. http://qed.emcdda.eu.int/resources/work groups/trends/trends.PDF (accessed on 04/May/ 2005).

13. Programa Nacional de Lucha contra el Retrovirus del Humano, SIDA y ETS, Ministerio de Salud de la Nación. Situación de la epidemia de SIDA en Argentina. Boletín sobre el SIDA en la Argentina 2004; XI(23):15.
14. Sosa-Estani S, Rossi D, Weissenbacher M. Epidemiology of HIV/AIDS in injecting drug users in Argentina: high seroprevalence of HIV infection. Clin Infect Dis 2003; 37 Suppl 5:338-42.

15. Caiaffa WT, Bastos FI. Usuários de drogas injetáveis e infecção pelo vírus da imunodeficiência humana: epidemiologia e perspectivas de intervenção. Rev Bras Epidemiol 1998; 1:190-202.

16. Osimani ML, Guchin M Usuarios de drogas inyectables. Prácticas de riesgo y prevalencia de infecciones por VIH, hepatitis B y hepatitis C. Montevideo: Instituto IDES; 2004.

17. Rossi D, Radulich G, Martínez-Peralta L, Sosa-Estani S, Vila M, Vivas L, et al. Riesgo de transmisión de VIH y otros virus en usuarios de drogas inyectables no institucionalizados del Gran Buenos Aires In: Reducción de daños. Apuntes para la acción [CD-ROM]. Buenos Aires: Asociación Civil Intercambios y Cooperación Alemana para el Desarrollo; 2002.

18. Moscatello G, Campello P, Benetucci J. Bloodborne and sexually transmitted infections in drug users in a hospital in Buenos Aires, Argentina. Clin Infect Dis 2003; 37 Suppl 5:343-7.

19. Linas B, Vila M. iEs posible tratar a los usuarios de drogas con terapias aintirretroviales? Infosida 2002; 2:24-8.

20. Kohli R, Lo Y, Howard AA, Buono D, Floris-Moore $\mathrm{M}$, Klein RS, et al. Mortality in an urban cohort of $\mathrm{HIV}$-infected and at-risk drug users in the era of highly active antiretroviral therapy. Clin Infect Dis 2005; 41:864-72.

21. Wang C, Vlahov D, Galai N, Bareta J, Strathdee SA, Nelson KE, et al. Mortality in HIV-seropositive versus seronegative persons in the era of highly active antiretroviral therapy: implications for when to initiate therapy. J Infect Dis 2004; 190: 1046-54.

22. Maulen S. Causas actuales de la mortalidad por sida en la Ciudad de Buenos Aires ¿De qué mueren los que mueren de sida? Infosida 2004; 4:68-70.

23. Lurie P, Reingold AL, editors. The public health impact of needle exchange programs in the United States and abroad. Conclusions and recommendations. San Francisco: University of California, San Francisco, Institute for Health Policy Studies; 1993.

24. Paone D, Des Jarlais D, Caloir S, Friedman PB, Ness I, Friedman SR. New York City syringe exchange: an overview. In: Proceedings of the National Academy of Sciences Workshop on Needle Exchange and Bleach Distribution Programs. Washington DC: National Academies Press; 1994. p. 47-63.

Submitted on 23/May/2005

Final version resubmitted on 29/Aug/2005

Approved on 06/Sep/2005 